\title{
An experimental study on effects of pyrrolidine dithiocarbamate on ischemia-reperfusion injury in testis
}

\author{
Eray Kemahli, MD; Mevlüt Yildiz, MD; Tülin Firat, MD; Mehmet Emin Özyalvaçli, MD; Uğur Üyetürk, MD; Burak \\ Yilmaz, MD; Adnan Gücük, MD
}

Abant Izzet Baysal University, School of Medicine, Turkey

Cite as: Can Urol Assoc J 2016;10(3-4):E104-9. http://dx.doi.org/10.5489/cuaj.3160

\section{Abstract}

Introduction: The aim of this experimental study was to investigate the histopathological and biochemical effects of pyrrolidine dithiocarbamate, an antioxidant and inhibitor of NF-k $\beta$, on ischemiareperfusion injury in rats.

Methods: A total of 21 male Wistar-Albino rats were randomly distributed into three groups as sham group (Group 1), ischemia-reperfusion (I/R) group (Group 2) and I/R with pyrrolidine dithiocarbamate (PDTC) group (Group 3). Left testicles of rats in Groups 2 and 3 underwent testicular torsion of $720^{\circ}$ for four hours and $100 \mathrm{mg} /$ $\mathrm{kg}$ of PDTC was administered intraperitoneally prior to detorsion in Group 3. An hour after detorsion process, left orchiectomies were performed and $5 \mathrm{ml}$ of intracardiac blood samples were drawn from rats in all three groups. Histopathological examination of testis tissues performed and measurement of superoxide dismutase (SOD) and malondialdehyde (MDA) levels in blood samples were taken. Results: Elevated levels of MDA and decreased SOD activity, together with decreased Johnson tubular biopsy scores consistent with $\mathrm{I} / \mathrm{R}$ injury were observed in Group $2(\mathrm{p}<0.05)$. Group 1 and Group 3 were similar in terms of MDA levels, SOD activity, and Johnson scores ( $p>0.05)$.

Conclusions: Our results indicated that PDTC may have beneficial effects for alleviation of $\mathrm{I} / \mathrm{R}$ injury in testicular tissue in rats. Understanding the underlying mechanisms and exploration of its diagnostic and therapeutic potential requires further randomized, controlled trials on a larger scale.

\section{Introduction}

Testicular torsion is a urological emergency that occurs mostly in adolescence and childhood. Its prevalence in males younger than 25 years is 1:4000 and it constitutes $25-35 \%$ of acute scrotal diseases of childhood. Unless diagnosis is established on time, testicular torsion may result in loss of testicular function and infertility. Ischemia due to testicular torsion in conjunction with reperfusion after detorsion are the underlying mechanisms for testicular injury. Failure of metabolic supply, owing to the dimunition of oxygen in ischemia, decreased cellular stores, and accumulation of toxic metabolites lead to germ cell death. ${ }^{1}$ Rotation of spermatic cord is initially accompanied by edema attributed to venous and lymphatic obstructions. Advancement of obstruction impedes arterial circulation, which is followed by testicular infarct. Tissue injury that occurs in testicular torsion is related to the degree and duration of testicular torsion. ${ }^{2}$ Experimental studies have shown that spermatogonia and spermatocytes are the most sensitive cells for testicular ischemia. $^{3}$

Free-oxygen radicals are linked with ischemia reperfusion $(\mathrm{I} / \mathrm{R})$ injury. ${ }^{1}$ These free-oxygen radicals exert their deleterious effects by destruction of the structural elements of the cell. Various antioxidants, like vitamin E, allopurinol, and melatonin, have been used to alleviate the hazardous impacts of free-oxygen radicals. ${ }^{4}$

$\mathrm{NF \kappa B}$ protein complexes are associated with immune response, inflammatory process, cellular proliferation, and apoptosis. ${ }^{5}$ Pyrrolidine dithiocarbamate (PDTC) is a specific inhibitor of NFKB. ${ }^{6}$ Activation of NFKB by interleukin-1, tumour necrosis factor- $\alpha$, and lipopolysaccharides has been blocked by administration of PDTC in human lymphocytic cell cultures. ${ }^{7}$

To the best of our knowledge, effects of PDTC on I/R injury in a testicular torsion model has not been studied in the literature. Therefore, the aim of this experimental study is to evaluate the histopathological and biochemical effects of PDTC on I/R injury due to testicular torsion.

\section{Methods}

\section{Experimental design}

This experimental study was carried out in the experimental research laboratory after the approval of the Institutional Animal Care and Use Committee of our institution (2013/33). Animals were kept at constant temperature $\left(20-22^{\circ} \mathrm{C}\right)$ and 
humidity (50-60\%) with a diurnal cycle of 12-hour day and 12-hour night periods. Animals were purchased from the facilities of our experimental research laboratory. Access to standard pellet food ( $210 \mathrm{kcal} / 100 \mathrm{~g} /$ day $)$ and tap water was provided ad libitum. All procedures were performed with respect to the guidelines of the National Institute of Health guide for the care and use of laboratory animals (NIH Publication No. 8023, revised 1978). A total of 21 male Wistar Albino rats (weighing 200-250 grams) that were three months old were used in this study. Histopathological examinations were done in the histology department of our institution, while analysis of blood samples was implemented in the biochemistry department.

Test animal were divided ino three groups, with each group consisting of seven rats. Procedures administered in each group were as follows: Group 1 (control) underwent left orchiectomy after scrotal incision without any additional surgical interventions. In Group 2, left testis was dissected after left scrotal incision and testicular torsion was accomplished by a counterclockwise rotation of $720^{\circ}$. Four hours after fixation of testis onto medial and lateral scrotal walls using 5/0 silk sutures, detorsion was made and reperfusion was allowed for one hour. At the end of one hour, testis was dissected and sent for histopathological examination. In Group 3, all procedures in Group 2 were performed. In addition, PDTC was administered intraperitoneally at a dose of $100 \mathrm{mg} / \mathrm{kg} 15$ minutes prior to reperfusion.

For biochemical analysis, $5 \mathrm{ml}$ of blood samples were obtained from all rats. Sacrification was made by decapitation after application of high-dose anesthetics.

\section{Biochemical assay}

Serum levels of superoxide dismutase (SOD) and malondialdehyde (MDA) were measured using colorimetric method and commercially available kits (Cayman Chemical Company, MI, U.S.).

\begin{tabular}{cc}
\hline Table 1. Johnsen tubular biopsy score \\
\hline Score & Definition \\
\hline 10 & Complete spermatogenesis with many spermatozoa \\
9 & Disorganized spematogenesis with many spermatozoa \\
8 & Only a few spermatozoa $(<5-10 /$ tubule $)$ \\
7 & No spermatozoa, many spermatids \\
6 & Only a few spermatids $(<5-10 /$ tubule $)$ \\
5 & No spermatids, many spermatocytes \\
4 & Only a few spermatocytes $(<5 /$ tubule $)$ \\
3 & Only spermatogonia \\
2 & Only Sertoli cells \\
1 & No cells detected in tubular section \\
\hline
\end{tabular}

\section{Histopathological examination}

After fixation of tissues in $10 \%$ formaldehyde solution for 24 hours, subsequent steps of irrigation and applications of alcohol and xylol were made. Paraffin blocks with thicknesses of 4-5 $\mu \mathrm{m}$ were stained with hematoxylin-eosin and Masson's trichrome stains.

Evaluation of changes in seminiferous tubules in three groups was made on a 1-10 scoring system, as described by Johnsen et al (Table 1). ${ }^{8}$ Seminiferous tubule diameters were measured on four different points in 10 tubules using Nikon Eclipse 80 i microscope (Nikon Instruments Europe B.V, Amsterdam, The Netherlands) using NIS-Elements D 3.2 program (Nikon Instruments Europe B.V, Amsterdam, The Netherlands). Number of apoptotic cells was assessed with TUNEL method using a commercially available Gen Script L00290 kit (GenScript USA Inc., Piscataway, NJ, U.S.).

\section{Statistical analysis}

Analysis of data was made using Statistical Package for Social Sciences program version 17.0 (SPSS Inc.,Chicago, IL, U.S.). Kruskal-Wallis variance analysis was used for SOD and MDA values, while comparison between groups was performed by means of Mann-Whitney $U$ test.

\section{Results}

\section{Biochemical results}

An overview of results derived from biochemical analysis of sera is presented in Table 2. Comparison of groups in terms of MDA and SOD values revealed a remarkable difference $(p=0.007$ for MDA, $p=0.020$ for SOD). With respect to MDA levels, there were significant differences between Groups 1 and $2(p=0.006)$ and Groups 2 and $3(p=0.025)$. In contrast, MDA levels were similar in Groups 1 and $3(p=0.142)$.

With respect to levels of SOD, there were noteworthy differences between Groups 1 and $2(p=0.014)$ and Groups 2 and $3(p=0.020)$. However, SOD levels did not display a notable difference between Groups 1 and $3(p=0.564)$.

\begin{tabular}{|c|c|c|}
\hline Groups & MDA & SOD \\
\hline 1 vs. 2 & $\mathrm{p}=0.006^{*}$ & $\mathrm{p}=0.014^{*}$ \\
\hline 1 vs. 3 & $\mathrm{p}=0.142$ & $p=0.564$ \\
\hline 2 vs. 3 & $\mathrm{p}=0.025^{*}$ & $\mathrm{p}=0.020^{*}$ \\
\hline
\end{tabular}


Kemahli et al.

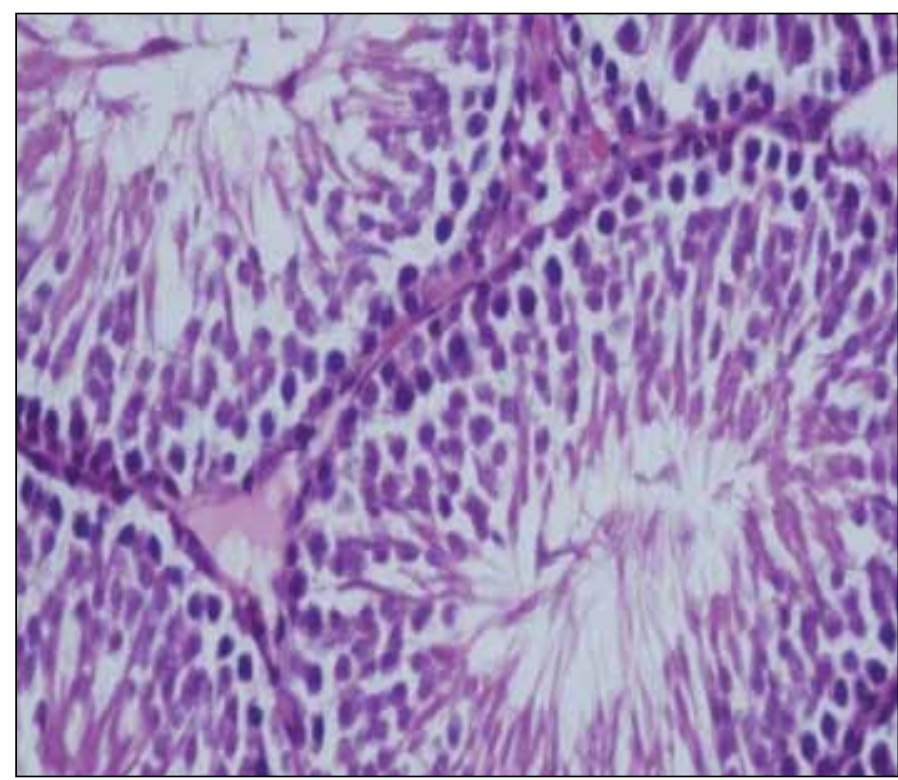

Fig. 1. Normal histological structures of seminiferous tubules and interstitial areas preserved in Group 1 (Hematoxylin-eosin X 200).

\section{Histopathological results}

The structural alterations in three groups are shown in Figs. 1-4. Testicular duration that lasted for four hours brought about macroscopic discolouration due to ischemia and edema. Seminiferous tubules appeared normal in Group 1. In Group 2, reduction of number of spermatozoa, disruption of tubuler epithelium, formation of debris formed due to accumulation of immature spermatogenetic cells in tubular lumen, edema, congestion, and atrophy were observed. Histopathological findings for seminiferous tubules in Group 3 were similar with those in Group 1; however, there was a decrease in number of spermatozoa in several sections in Group 3.

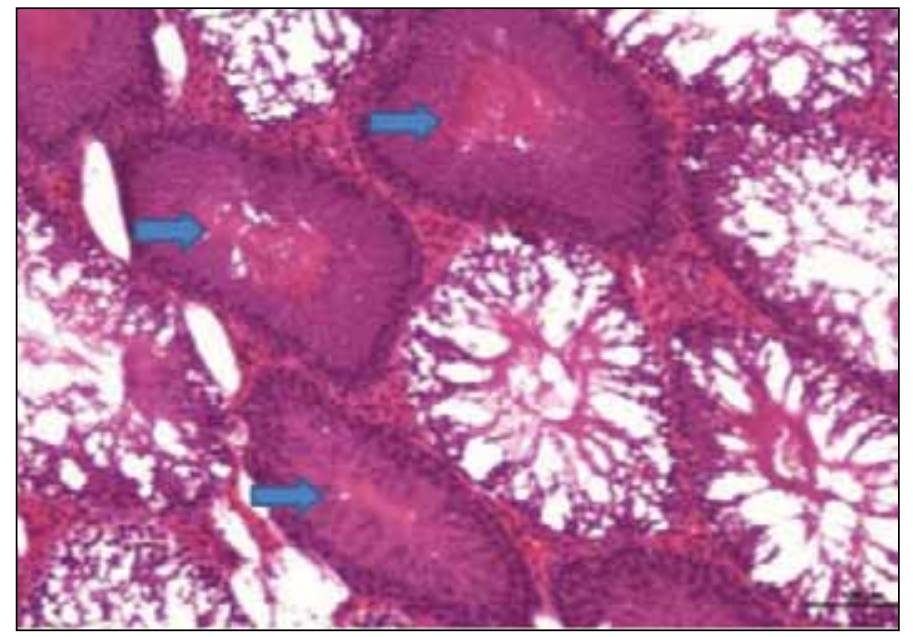

Fig. 3. Tubular necrosis (arrows) in Group 2 (Hematoxylin-eosin X 200).

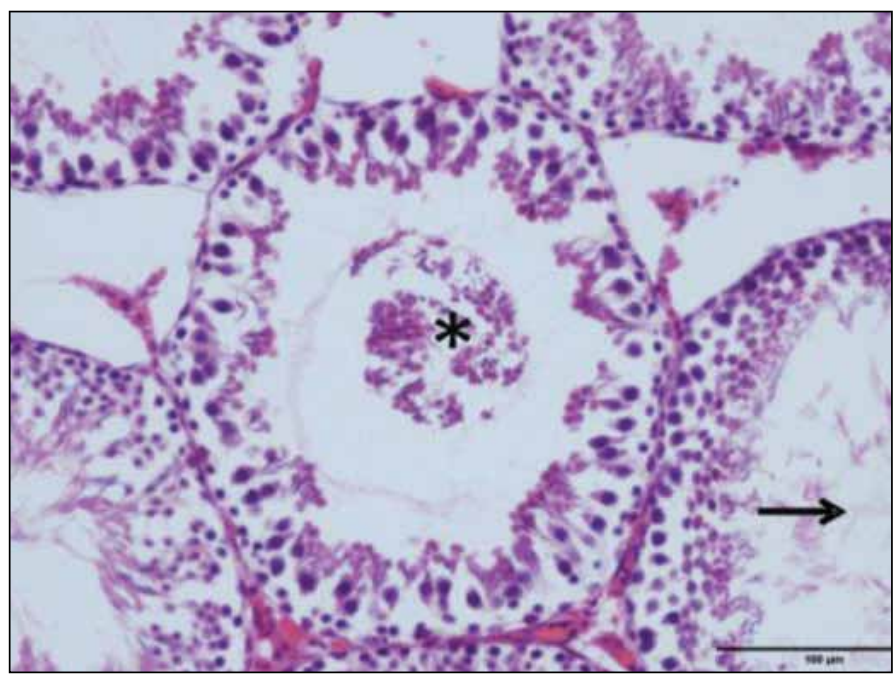

Fig. 2. Epithelial irregularity, decreased number of spermatozoa (arrow) and debris formation in lumen due to accumulation of immature spermatogenetic cells (asterisk) in Group 2 (Hematoxylin-eosin X 200).

Diameters of seminiferous tubules were reduced in Group 2, whereas Groups 1 and 3 displayed similar findings. Only a few apoptotic cells were detected in Groups 1 and 3, while there was a noteworthy increase in their number in Group 2.

Comparison of groups with respect to Johnsen score, diameter of seminiferous tubules, and number of apoptotic cells are demonstrated in Figs. 5-7. It turned out there were significant differences between Groups 1 and $2(p=0.001)$ and Groups 2 and $3(p=0.005)$ regarding Johnsen scores. Similarly, remarkable differences were observed between Groups 1 and $2(p=0.002)$ and Groups 2 and $3(p<0.001)$ with respect to diameters of seminiferous tubules. In the same fashion, noteworthy differences were observed between Groups 1 and $2(p=0.001)$ and Groups 2 and 3 in terms of number of apoptotic cells.

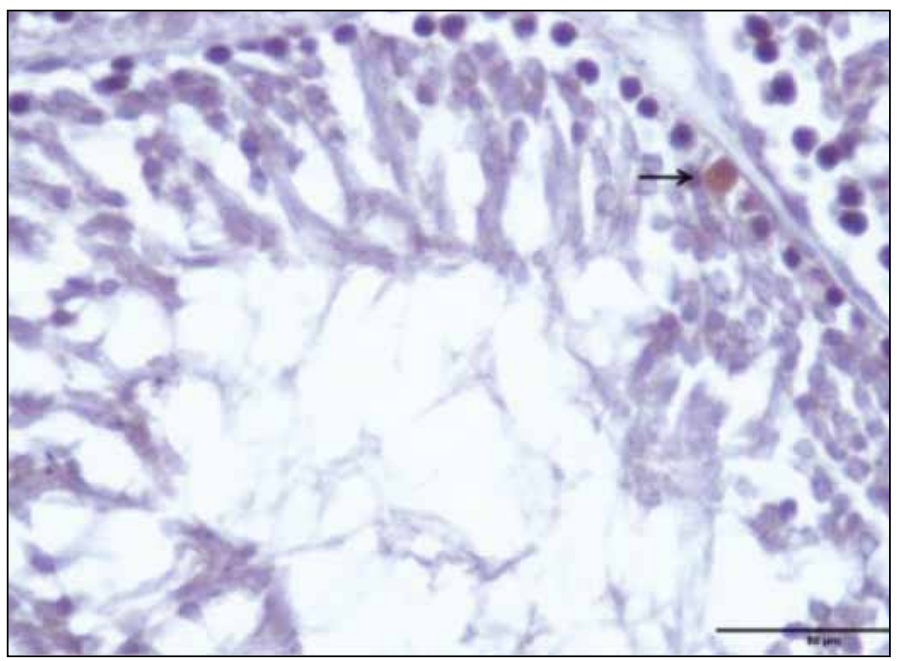

Fig. 4. Apoptotic cells (arrow) are observed rarely in Group 3. 
PDTC and ischemia-reperfusion injury in testis

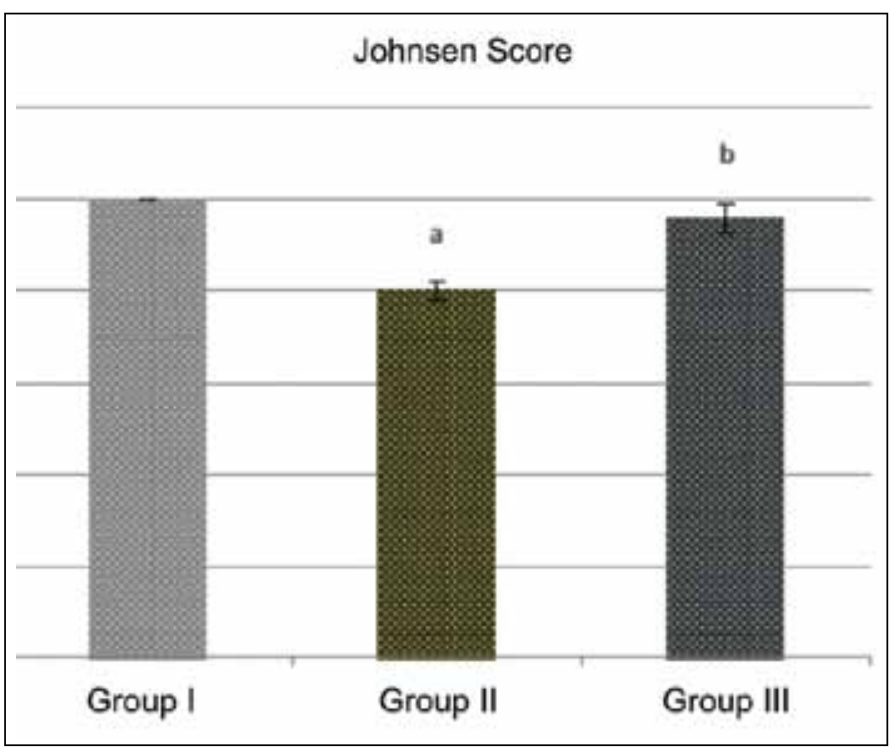

Fig. 5. Overview of Johnsen scores in study and control groups. asignificant difference between Group I and Group II ( $p=0.001)$; 'bignificant difference between Group II and Group III ( $\mathrm{p}=0.005$ ); no significant difference between Group I and Group III ( $\mathrm{p}=0.142)$.

\section{Discussion}

In the current study, we aimed to investigate the effects of PDTC on histopathological parameters and serum levels of MDA and SOD in $\mathrm{I} / \mathrm{R}$ injury from an experimental testicular torsion model. Our results imply that PDTC may have beneficial effects for alleviation of the deleterious effects of $\mathrm{I} / \mathrm{R}$ injury.

A complete cessation of blood flow and ischemia can occur due to a testicular torsion of $720^{\circ}$, with a resultant hypoxia and necrosis of germinal cells. Experimental studies demonstrated that these changes may be reversible in the first four to six hours after onset. Therefore, timely diagnosis and appropriate intervention without delay are key points in the management of testicular torsion. ${ }^{9}$

Etiology of ischemic injury formed during testicular torsion is associated with inflammation and oxidative stress. Detorsion of testis is followed by reperfusion and oxygenation characterized by increased free-oxygen radicals and reactive nitrogen radicals. These biochemical changes cause toxic effects, such as lipid peroxidation, protein oxidation, and oxidative damage on DNA. ${ }^{10} \mathrm{MDA}$ is one of the markers of this oxidative damage and its levels are elevated in tissues exposed to I/R injury. ${ }^{11}$ Superoxide dismutase is an antioxidant enzyme that converts toxic superoxide radicals to molecular oxygen and hydrogen peroxide. Similar to MDA, SOD activity reflects the oxidative stress in tissue. ${ }^{12}$

Alternative medications that may aid in restoration of reperfusion injury after restoration have been investigated. Nevertheless, no consensus could be established on the indications, effectivity, dosage, and duration of these molecules on alleviation of $\mathrm{I} / \mathrm{R}$ injury. ${ }^{5,11,12}$

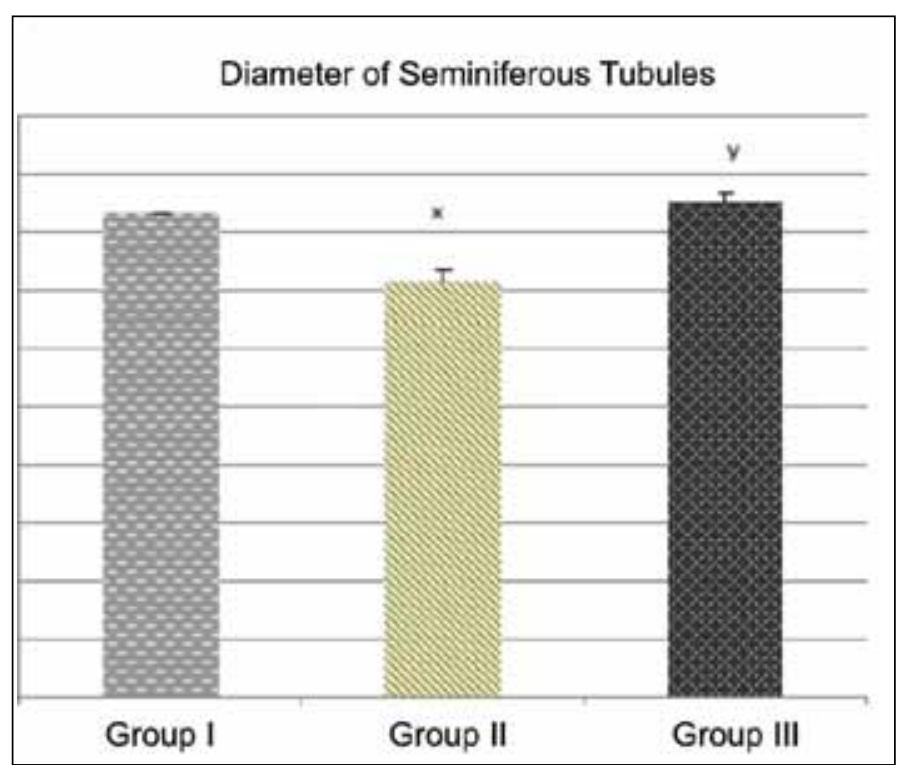

Fig. 6. Overview of diameters of seminiferous tubules in study and control groups. ${ }^{\mathrm{x}}$ significant difference between Group I and Group II ( $\left.p=0.002\right)$; ${ }^{y}$ significant difference between Group II and Group III ( $\left.p=0.006\right)$; no significant difference between Group I and Group III ( $p=0.786)$.

Pyrrolidine dithiocarbamate is a low-molecular weight thiol compound used as an antioxidant against the toxic impacts of free radicals. This beneficial effect of PDTC is linked with its thiol group, which acts by neutralizing reactive oxygen species. Its biochemical activities, including alternation of redox state, chelation of heavy metals, and inhibition of enzymes are well studied. Therefore, antioxidant and therapeutic application of PDTC in diseases involving the production of free radicals are known. Consequently, PDTC reduces the production of inflammatory cytokines. ${ }^{13}$

Protective role of PDTC against I/R injury was the main concern of the current study. Previous reports have documented the beneficial effects of PDTC in testicular injury due to cisplatin, renal damage attributed to extracorporeal shock wave lithotripsy, acute respiratory distress syndrome, and focal cerebral ischemia. ${ }^{14-17}$ Controversial reports exist on effects of PDTC on apoptosis. ${ }^{18}$

Significant contribution may be obtained from the effects of PDTC for alleviation and restoration of $\mathrm{I} / \mathrm{R}$ injury in testis. Hopefully, our results may inspire further trials investigating the applications of PDTC in other diseases associated with $\mathrm{I} / \mathrm{R}$ injury.

This trial is the first study investigating the histopathological and biochemical effects of PDTC on I/R injury in testis. Our results show that PDTC may have a protective role against histopathological and biochemical deleterious effects of $\mathrm{I} / \mathrm{R}$ injury. Therefore, further controlled trials on a larger series of subjects must be performed to explore and interpret the clinical implications of data derived from the present study. 


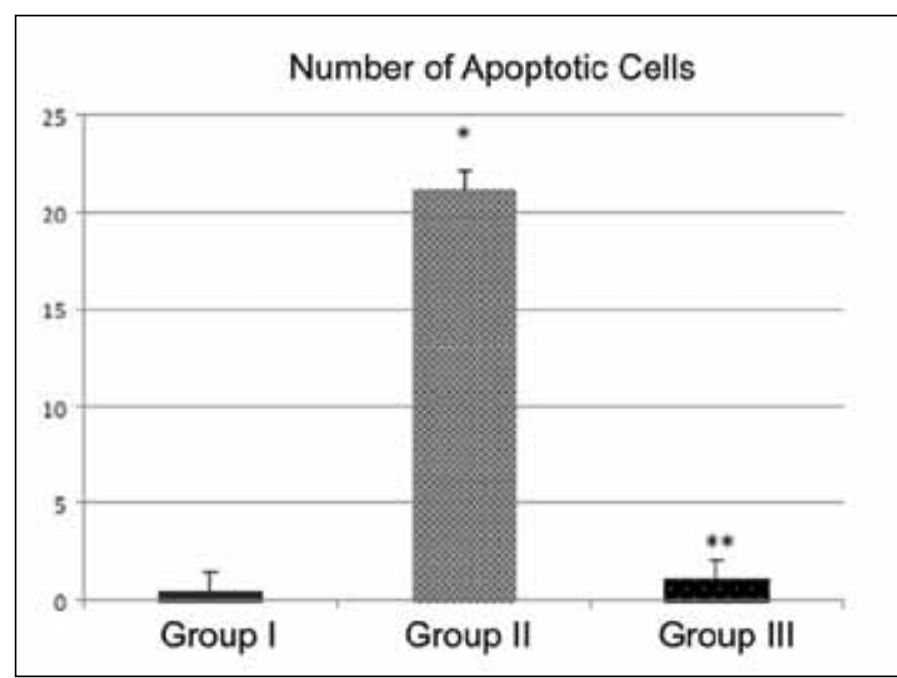

Fig. 7. Comparative view of diameters of seminiferous tubules in study and control groups. "significant difference between Group I and Group II ( $p=0.001)$; ** significant difference between Group II and Group III ( $p=0.002$ ); no significant difference between Group I and Group III ( $p=0.226)$.

Restrictions due to technical and environmental factors must be kept in mind before extrapolation of these results. From this point of view, lack of analysis of other indicators of oxidative stress constitutes an important limitation.

The histopathological effects of $I / R$ injury in testis by number of apoptotic cells and Johnson scores has been previously reported by several authors. ${ }^{19}$ In the literature, biochemical consequences of $\mathrm{I} / \mathrm{R}$ have been associated with levels of MDA. 10,20,21 Increased MDA levels are consistent with increased lipid peroxidation in I/R injury. Similarly, SOD is an enzyme that functions to re-establish the balance after oxidative stress injury and, therefore, it may serve as an indicator for oxidative stress. ${ }^{22}$

In previous studies, it's been shown that there were some histopathological changes and a decrease in testicular perfusion not only in ipsilateral torted, but also in the contralateral nontorted testis. ${ }^{23,24}$ The agents used for prevention of $\mathrm{I} / \mathrm{R}$ damage on ipsilateral testis also have beneficial effects on contralateral testis. ${ }^{23,24}$ These results could have clinical relevance in the clinical scenario of a necessary orchiectomy. We didn't investigate the contralateral testis and this can be a pitfall of our study; investigation of both testis can improve the quality and accuracy of future studies.

\section{Conclusion}

Results of the present experimental study have demonstrated that PDTC has beneficial effects at both histopathological and biochemical levels against $\mathrm{I} / \mathrm{R}$ injury. Application of PDTC amplifies the antioxidant system by lowering MDA levels and increasing SOD activity, as well as diminishing apoptotic cells and improving Johnson scores of tubular biopsy specimen. All in all, PDTC has displayed promising results as an adjunctive therapeutic measure in I/R injury in testis. Further trials are warranted for documentation of actual effectivity and determination of dose, duration, and route of application.

Competing interests: The authors declare no competing financial or personal interests.

Acknowledgements: Financial support was received from Abant lzzet Baysal University Scientific Research Project Fund (№: 2014.08.20.696).

This paper has been peer-reviewed.

\section{References}

1. Mogilner JG, Lurie $M$, Coran AG, et al. Effect of diclofenac on germ cell apoptosis following testicular ischemia-reperfusion injury in a rat. Pediatr Surg Int 2006;22:99-105. http://dx.doi.org/10.1007/ s00383-005-1580-9

2. Turner TT, Brown KJ. Spermatic cord torsion: Loss of spermatogenesis despite return of blood flow. Biol Reprod 1993;49:401-7. http://dx.doi.org/10.1095/biolreprod49.2.401

3. Cay A, Alver A, Kucuk $M$, et al. The effects of nacetylcysteine on antioxidant enzyme activities in experimental testicular torsion. J Surg Res 2006;131:199-203. http://dx.doi.org/10.1016/i. iss.2005.11.572

4. Abasiyanik A, Dagdonderen L. Beneficial effects of melatonin compared with allopurinol in experimental testicular torsion. J Ped Surg 2004;39:1238-41. http://dx.doi.org/10.1016/i.jpedsurg.2004.04.018

5. Ahn KS, Sethi G, Aggarwal BB. Nuclear factor-kappa B: From clone to clinic. Curr Mol Med 2007;7:619-37. http://dx.doi.org/10.2174/156652407782564363

6. Schreck R, Rieber P, Baeverle PA. Reactive oxygen intermediates as apparently widely used messengers in the activation of the NF-kappa B transcription factor and HIV-1. EMBO J 1991;10:2247-58.

7. Schreck R, Meier B, Mannel DN, et al. Dithiocarbamates as potent inhibitors of nuclear factor kappa B activation in intact cells. J Exp Med 1992;175:1181-94. http://dx.doi.org/10.1084/jem.175.5.1181

8. Johnsen SG. Testicular biopsy score count-a method for registration of spermatogenesis in human testes: Normal values and results in 335 hypogonadal males. Hormones 1970;1:2-25. http://dx.doi. org/10.1159/000178170

9. Turner TT, Bang HJ, Lysiak JJ. Experimental testicular torsion: Reperfusion blood flow and subsequent testicular venous plasma testosterone concentrations. Urology 2005;65:390-4. http://dx.doi.org/10.1016/i. urology.2004.09.033

10. Yagmurdur $\mathrm{H}$, Ayyldiz A, Karaguzel E, et al. The preventive effects of thiopental and propofol on testicular ischemia-reperfusion injury. Acta Anaesthesiol Scand 2006;50:1238-43. http://dx.doi.org/10.1111/ j.1399-6576.2006.01145.x

11. Abes $M$, Sarnhan $H$, Değer 0 , et al. The effect of ATPMgCl(2) on prevention of reperfusion injury after unilateral testicular torsion. Eur J Pediatr Surg 2001;11:255-8. http://dx.doi.org/10.1055/s-2001-17146

12. Beheshtian A, Salmasi AH, Payabvash S, et al. Protective effects of sildenafil administration on testicular torsion/detorsion damage in rats. World J Urol 2008;26:197-202. http://dx.doi.org/10.1007/ s00345-008-0243-6

13. Ding $H$, Zhu $T$, Yin $X$, et al. Pyrrolidine dithiocarbamate protects pancreatic $\beta$-cells from oxidative damage through regulation of FoxO1 activity in type 2 diabetes rats. Acta Biochim Biophys Sin (Shanghai) 2014;46:582-9. http://dx.doi.org/10.1093/abbs/gmu034

14. Ilbey YO, Ozbek E, Simsek A, et al. Chemoprotective effect of a nuclear factor-kappaB inhibitor, pyrrolidine dithiocarbamate, against cisplatin induced testicular damage in rats. J Androl 2009; 30:505-14. http:// dx.doi.org/10.2164/jandrol.108.006270

15. Tugcu V, Bas M, Ozbek E, et al. Pyrolidium dithiocarbamate prevents shockwave lithotripsy-induced renal injury through inhibition of nuclear factor-kappa $B$ and inducible nitric oxide synthase activity in rats. I Endourol 2008;22:559-66. hitp://dx.doi.org/10.1089/end.2007.0295

16. Wang $M$, Liu $T$, Wang $D$, et al. Therapeutic effects of pyrrolidine dithiocarbamate on acute lung injury in rabbits. J Transl Med 2011;9:61. http://dx.doi.org/10.1186/1479-5876-9-61

17. Li J, Sheng $W$, Feng $C$, et al. Pyrrolidine dithiocarbamate attenuates brain A $\beta$ increase and improves long-term neurological outcome in rats after transient focal brain ischemia. Neurobiol Dis 2012;45:564-72. http://dx.doi.org/10.1016/i.nbd.2011.09.013 
18. Arima N, Arimura K, Tokito Y, et al. HTLV-I Tax protein inhibits apoptosis induction but not Gl arrest by pyrrolidinedithiocarbamate, an antioxidant, in adult T cell leukemia cells. Exp Hematol 2004;32:195-201. http://dx.doi.org/10.1016/i.exphem.2003.11.008

19. Yuluğ $E$, Türedi $S$, Karagüzel $E$, et al. The short-term effects of resveratrol on ischemia-reperfusion injury in rat testis. J Pediatr Surg 2014;49:484-9. http://dx.doi.org/10.1016/i.jpedsurg.2013.08.028

20. Kehinde E0, Anim JT, Mojiminiyi OA, et al. Allopurinol provides long-term protection for experimentally induced testicular torsion in a rabbit model. BJU Int 2005;96:175-80. http://dx.doi.org/10.1111/ j.1464-410X.2005.05590.x

21. Koksal $M, O \breve{g} u z E$, Baba F, et al. Effects of melatonin on testis histology, oxidative stress and spermatogenesis after experimental testis ischemia reperfusion in rats. Eur Rev Med Pharmacol Sci 2012;16:582-8.
22. Ozkan KU, Boran C, Kilinc M, et al. The effect of zinc aspartate pretreatment on ischemia-reperfusion injury and early changes of blood and tissue antioxidant enzyme activities after unilateral testicular torsion-detorsion. J Pediatr Surg 2004;39:91-5. http://dx.doi.org/10.1016/i.jpedsurg.2003.09.013

23. Tuglu D, Yuvanc E, Yilmaz E, et al. The antioxidant effect of dexmedetomidine on testicular ischemiareperfusion injury. Acta Cir Bras 2015;30(6):414-21.

24. Cvetkovic T, Stankovic J, Naiman S, et al. Oxidant and antioxidant status in experimental rat testis after testicular torsion/detorsion. Int J Fertil Steril 2015;9(1):121-8.

Correspondence: Dr. Eray Kemahli, Abant Izzet Baysal University, School of Medicine, Turkey; eraykemahli@hotmail.com 